\title{
Clinicopathological Profile of Thyroid Carcinomas: A 10-Year Experience in a Tertiary Care Institute
}

\author{
Bahri Özer ${ }^{1}$, Oğuz Çatal ${ }^{1}$, Songül Peltek Özer ${ }^{2}$, Mustafa Sit $^{1}$, Hayri Erkol $^{1}$ \\ ${ }^{1}$ Abant Izzet Baysal University Hospital, Department of General Surgery, Bolu, Turkey \\ ${ }^{2}$ Abant Izzet Baysal University Izzet Baysal Traınıng and Research Hospıtal, Department of Pathology, Bolu, Turkey
}

Received: 13 November 2019, Accepted: 30 March 2020, Published online: 30 April 2020

(C) Ordu University Institute of Health Sciences, Turkey, 2020

\begin{abstract}
Objective: Thyroid gland is an important endocrine gland and thyroid cancers (TC) are the most noteworthy disease of the thyroid gland. Although thyroid surgery is performed for most particularly for malignancy, thyroidectomies still maintain a large part of surgical operations. We aimed to investigate the incidence and subtypes of the thyroid cancers in present study, with our 10 years' experience of thyroid surgery.

Methods: Data of patients who underwent thyroidectomy were retrospectively analyzed. The patients who underwent bilateral total thyroidectomy were included to the study. Patients' age, gender and histopathological results were recorded. According to the histopathological reports we divided the patients into two groups either as benign or malignant.

Results: A total of 3632 patients were included in the study. 2999 (82.6\%) patients were in benign group and 633(17.4\%) patients were in malignant group. The subtypes of malignant tumors were papillary carcinoma in 591 (93.4\%), medullary carcinoma in 16 (2.5\%), follicular carcinoma in 14 (2.2\%), oncocytic (hurtle cell) carcinoma in $7(1.1 \%)$ and undifferentiated (anaplastic) in $5(0.8 \%)$ of the cases.

Conclusion: Incidental thyroid cancers are not a rare entity after pathological examination of thyroid specimen after surgery. Therefore, we suggest careful evaluation and bilateral leb lobectomy ectomy in surgical treatment of thyroid conditions
\end{abstract}

Key words: Thyroid, Benign, Malignant, Multicentricity

Suggested Citation: Ozer B, Catal O, Peltek Ozer S, Sit M, Erkol H. Clinicopathological Profile of Thyroid Carcinomas: A 10-Year Experience in a Tertiary Care Institute. Middle Black Sea Journal of Health Science, 2020; 6(1):24-27.

\section{Address for correspondence/reprints:}

Bahri Özer

Telephone number: +90 (530) 2851494

ORCID-ID 0000-0002-4326-2102

E-mail: bahriozer@ hotmail.com

DOI: $10.19127 / \mathrm{mbsjohs.646535}$

\section{Introduction}

Thyroid gland is an important endocrine gland associated with plenty of diseases which are classified as congenital, genetic and sporadic. Surgery is indicated when cosmetic problems, compression symptoms and malignancy is the case. Although thyroid surgery is performed as the most particularly for malignancy, thyroidectomies for other reasons still maintain a large part of surgical interventions of the thyroid gland. However, there might be establishment of diagnosis of malignancy or a suspicion for malignancy before the surgery, incidental cancers should also be encountered by physicians. Thyroid cancers (TC) are the most 
important diseases of the thyroid gland. İt is the most prevailing malignant tumor of the endocrine system (Hu et al., 2018). İt constitutes approximately $1 \%$ of all human malignancies and is the main cause of mortality among endocrine tumor-related deaths(Are \& Shaha, 2006) İn 2010, Jemal et al. reported 44700 new cases of thyroid cancers per year, worldwide, and 1700 deaths annually due to thyroid cancer(Jemal, Siegel, Xu, \& Ward, 2010) Annual increase of 5.3\% in TC incidence was reported by Magreni et al. in 2015 (Magreni, Bann, Schubart, \& Goldenberg, 2015). Despite vast majority of thyroid cancers have low mortality and morbidity, aggressive cancer types of thyroid gland should not be ignored.

We aimed to investigate the incidence and subtypes of the thyroid cancers in this study, with our 10 years experience of thyroid surgery.

\section{Methods}

We retrospectively analyzed the data of patients who underwent thyroidectomy between January 2008 and December 2017 in General Surgery Department of University Hospital. This work has been approved by the directorate of the institution date 02.03.2016/349. We included all subjects undergone thyroid surgery. Clinical and radiological records of all patients, especially thyroid sonography, laboratory tests and fine needle aspiration cytology (FNAC) results were recorded and evaluated. The patients who underwent bilateral total thyroidectomy were included the study. The patients with lobectomy were excluded. Patients' age, gender and histopathological results were recorded from the institutional database. According to the histopathological reports we divided the patients into two groups either as benign or malignant. The subtypes of malignant group were classified as papillary carcinoma, follicular carcinoma, medullary carcinoma, oncocytic (hurtle cell) carcinoma and undifferentiated (anaplastic) carcinoma. Malignant group was also investigated for tumor size and presence of multicentricity.

\section{Statistical Analyses}

The demographic parameters and pathological results of all patients were recorded and statistically analyzed by SPSS software (SPSS 15.0 for Windows, İBM İnc, Chicago, İL, USA). Comparison of the nonhomogenously distributed quantitative variables in study groups were compared by Mann-Whitney U Test and expressed as median (IQR) and qualitative variables were conducted by Chi-Square test and expressed as $\mathrm{n}(\%)$. A $\mathrm{p}$ value less than 0.05 was considered as statistically significant.

\section{Results}

A total of 3632 patients included to the study. $2999(82.6 \%)$ patients' histopathological results were benign and the average age of this group was $47.1 \pm 12.5$ years. $633 \quad(17.4 \%)$ patients' histopathological results were malignant with an average age of $47 \pm 12.6$ years. The age was not statistically significant between benign and malignant groups $(\mathrm{p}=0.711)$. Benign group consisted of 2399 $(80 \%)$ female and $600(20 \%)$ male while malignant group consisted of 509 (80.4\%) females and 124 (19.6\%) males. As shown in Table 1, gender was not statistically different between benign and malignant groups $(\mathrm{p}=0.811)$.

Table 1. Demographic results

\begin{tabular}{llccc}
\hline & & $\begin{array}{c}\text { Benign } \\
(\mathrm{n}=2999)\end{array}$ & $\begin{array}{c}\text { Malignant } \\
(\mathrm{n}=633)\end{array}$ & $\mathrm{p}$ \\
\hline Mean age & (years) & $47.1 \pm 12.5$ & $47 \pm 12.6$ & 0.711 \\
Gender & $\begin{array}{l}\text { Female } \\
(\mathrm{n}, \%)\end{array}$ & $2399(80 \%)$ & 509 & \\
& $\begin{array}{c}\text { Male } \\
(\mathrm{n}, \%)\end{array}$ & $600(20 \%)$ & $\begin{array}{c}124 \\
(19.6 \%)\end{array}$ & 0.811 \\
\hline
\end{tabular}

Median tumor diameter in malignant group was $15.75 \mathrm{~mm}(1-90 \mathrm{~mm})$. The tumor diameter was smaller than $10 \mathrm{~mm}$ in $319(50.3 \%)$ and bigger than $10 \mathrm{~mm}$ in $314(49.7 \%)$ of the cases in the malignant group. The subtypes of malignant tumors were as follows: papillary carcinoma in 591 (93.4\%), medullary carcinoma in 16 (2.5\%), follicular carcinoma in $14(2.2 \%)$, oncocytic (hurtle cell) carcinoma in $7(1.1 \%)$ and was undifferentiated (anaplastic) in $5(0.8 \%)$ of the cases.

The tumor was multicentric in 195 (30.8\%) and unicentric in 438 (69.2\%) cases in malignant group. Multicentrcity rates of subtypes were $31.1 \%(n=184)$ in papillary, $31.2 \%(\mathrm{n}=5)$ in medullary, $14.3 \%(\mathrm{n}=2)$ in follicular, $14.3 \%(n=2)$ in oncocytic (hurtle cell) and $60 \% \quad(n=3)$ in undifferentiated (anaplastic) carcinomas. The relationship between multicentricity and malignant subtypes was not statistically significant ( $\mathrm{p}=0.317)$.

Patients' histopathological results younger than 50 years of age were consisted of $1718(82.6 \%)$ benign and $361(17.4 \%)$ malignant. For the patients over 50 years of age, $1281(82.5 \%)$ were benign and 272 $(17.5 \%)$ were malignant tumors. As shown in table 2, malignancy rates of the subgroups according to the age (over or under 50 years) were not statistically different $(\mathrm{p}=0.906)$. 
Table 2. Histopathological Results

\begin{tabular}{llrrr}
\hline Malignant & & $\mathrm{n}$ & $\%$ & $\mathrm{p}$ \\
\hline Age (years) & $<50$ & 361 & 17.4 & 0.90 \\
& $>50$ & 272 & 17.5 & \\
\hline Tumor diameter & $<10$ & 319 & 50.3 & 0.81 \\
$(\mathrm{~mm})$ & $>10$ & 314 & 49.7 & \\
\hline \multirow{3}{*}{ papillary } & $591 /$ & 93.4 & 0.31 \\
& & 184 & 129. & \\
Tumor subtype & & & 1 & \\
and & & $16 / 5$ & $2.5 /$ & \\
multicentricity & follicular & $14 / 2$ & 0.8 & \\
& & & $2.2 /$ & \\
& oncocytic & $7 / 1$ & 0.3 & \\
& & & $0.1 /$ & \\
& anaplastic & $5 / 3$ & $0.8 /$ & \\
& & & 0.5 & \\
\hline
\end{tabular}

\section{Discussion}

Although the majority of the pathology results after thyroid surgery are benign conditions, the rate of malignancies is increasing day by day. The higher number of incidental malignant pathologies contribute to these increased rates. Rather than compression symptoms and cosmetic problems, main indications of thyroid surgery in recent years are established malignancy and malignancy suspicion. One of the promising results of thyroid surgery is that the prognosis of thyroid malignancies is better than other organ malignancies.

Thyroid surgery is the mostly performed in women. İn the literature, the ratio of women and men varies between 3.4-7.6\% (Akgun et al., 2007; Benek et al., 2015). İn our study this ratio was 4.1. The mean age of patients who underwent thyroid surgery ranged from 43 to 51 years in the literature (Benek et al., 2015; Lefevre et al., 2007). İn our study, the mean age was found to be 47 years. Although thyroid surgery is performed initially due to a benign disease, in histopathological examination 3-16.6\% of incidental cancer is detected (Efremidou, Papageorgiou, Liratzopoulos, \& Manolas, 2009; Erbil et al., 2006; Prades et al., 2002). İn our study, the rate of cancer in the whole series was found to be $17.4 \%$.

Thyroid cancers are generally classified into two categories as differentiated and undifferentiated. The most common subtypes are papillary cancers. Prognosis of papillary cancer is better than other subtypes. İn the differentiated thyroid cancer series of 1005 cases by Nickel B et al., the most common subtype was papillary cancer with a rate of $88.6 \%$ (Nickel et al., 2019). The most common pathologic diagnosis in thyroid surgery performed by Ohtsuru et al. was papillary cancer with a rate of $98 \%$ (Ohtsuru et al., 2019). Similar to the literature knowledge, in our series of 633 thyroid cancers, the most common pathologic diagnosis was papillary cancer (93.4\%). Today, due to the development and availability of diagnostic methods, thyroid cancer is diagnosed at micro $(<10 \mathrm{~mm})$ levels and even may be followed up without surgery. Papillary thyroid microcarcinoma (PTMC), accounts for 39\% of the cases of thyroid cancer in the USA and $43.1 \%$ of the cases in Korea (Davies \& Welch, 2014; Lee \& Shin, 2014). İn our study, we found the microcarcinoma ratio as high as $50.3 \%$. This is due to the advanced imaging and laboratory facilities of our institution as a tertiary referral hospital.

One of the most important problems in thyroid cancer is the multifocality of the tumors. Multicentricity of Papillary thyroid cancer is a welldescribed feature of this tumor, with estimated frequency range from $22 \%$ to $49 \%$ (Grigsby, Gal-or, Michalski, \& Doherty, 2002). İn our study, multicentricity rate was $30.2 \%$ in all patients diagnosed with thyroid cancer, and the rate of multicentricity in the papillary cancer was $31.2 \%$.

Retrospective design is a limitation of our study, however, important results of the present study suggesting literature knowledge may add significant contribution to the current medical literature.

\section{Conclusion}

Incidental thyroid cancers are not a rare entity after pathological examination of thyroid specimen after surgery. Therefore, we suggest careful evaluation and bilateral lobectomy in surgical treatment of thyroid conditions.

Ethics Committee Approval: Ethics committee approval was received for this study from Clinical Research Ethics Committee of Haseki Education and Research Hospital. (Date: 02.03.2016, Decision Number:349).

Peer-review: Externally peer-reviewed.

Author Contributions: Concept-B.O, O.C, S.P Design-B.O, M.S. H.E; Supervision-H.E.; FundingNone Materials- O.C, SP.; Data Collection/Data Process-B.O,O.C.; Analyze or Comment-M.S,H.E.; Literature Scanning-B.O, O.C, S.P; Writer of PaperB.O.; Critical Review-H.E, M.S.

Conflict of Interest: No conflict of interest was declared by the authors.

Financial Disclosure: The authors declared that this study hasn't received no financial support. 


\section{References}

Akgun Y, Ongoren A, Kuru S, Acar E, Cengiz A, \& Gulhan D. Tetany after thyroid surgery. Turkish Medical Journal, 2007;1:80-85.

Are C, \& Shaha A.R. Anaplastic thyroid carcinoma: biology, pathogenesis, prognostic factors, and treatment approaches. Annals of surgical oncology, 2006;13(4):453-464.

Benek S, Kocakusak A, Ozer B, Kizilkaya M.C., Erozgen, F, Ciftci F, Tatar C. The Ever-Changing Configuration of the Completion Thyroidectomy in the Last Decade. Haseki Tip Bulteni, 2015;53(3).

Davies L, \& Welch H.G. Current thyroid cancer trends in the United States. JAMA Otolaryngology-Head \& Neck Surgery, 2014;140(4): 317-322.

Efremidou E.I., Papageorgiou M.S, Liratzopoulos, N, \& Manolas K.J. The efficacy and safety of total thyroidectomy in the management of benign thyroid disease: a review of 932 cases. Canadian Journal of Surgery, 2009;52(1):39.

Erbil Y, Barbaros U, Salmaslioglu A, Yanık B.T, Bozbora A., \& Ozarmagan, S. The advantage of near-total thyroidectomy to avoid postoperative hypoparathyroidism in benign multinodular goiter. Langenbeck's archives of surgery, 2006;391(6):567-573.

Grigsby P.W, Gal-or A, Michalski J.M, \& Doherty, G.M. Childhood and adolescent thyroid carcinoma. Cancer: Interdisciplinary International Journal of the American Cancer Society, 2002;95(4):724-729.

Hu D, Zhou J, He W, Peng J, Cao Y, Ren H, Xiao Q. Risk factors of lateral lymph node metastasis in $\mathrm{cN} 0$ papillary thyroid carcinoma. World journal of surgical oncology, 2018;16(1):30.

Jemal A., Siegel R, Xu J, \& Ward E. Cancer statistics, 2010. CA: a cancer journal for clinicians, 2010;60(5):277-300.

Lee J.-H, \& Shin S.W. Overdiagnosis and screening for thyroid cancer in Korea. The Lancet, 2014;384(9957):1848.

Lefevre J.H., Tresallet C, Leenhardt L., Jublanc C., Chigot J.P., \& Menegaux F. Reoperative surgery for thyroid disease. Langenbeck's archives of surgery, 2007;392(6):685-691.

Magreni A, Bann D.V, Schubart J.R., \& Goldenberg D. The effects of race and ethnicity on thyroid cancer incidence. JAMA Otolaryngology-Head \& Neck Surgery, 2015;141(4): 319-323.
Nickel B, Tan T., Cvejic E, Baade P, McLeod D.S., Pandeya, N., Jordan, S. Health-Related quality of life after diagnosis and treatment of differentiated thyroid cancer and association with type of surgical treatment. JAMA Otolaryngology-Head \& Neck Surgery, 2019;145(3):231-238.

Ohtsuru A, Midorikawa S, Ohira T., Suzuki S., Takahashi H., Murakami M., Suzuki S. Incidence of thyroid cancer among children and young adults in Fukushima, Japan, screened with 2 rounds of ultrasonography within 5 years of the 2011 Fukushima Daiichi Nuclear Power Station accident. JAMA Otolaryngology-Head \& Neck Surgery, 2019;145(1): 4-11.

Prades J.M., Dumollard J.M., Timoshenko A, Chelikh L, Michel F, Estour B, \& Martin C. Multinodular goiter: surgical management and histopathological findings. European archives of oto-rhino-laryngology, 2002;259(4):217-221. 